\title{
Rancang Bangun Unit Pemotong dan Pengarah pada Mesin Panen Padi (Oryza sativa l) Tipe Carry Harvester
}

\section{Design of Cutting and Guiding Unit of Carry Type Paddy (Oryza sativa l) Harvester}

\author{
Ida Bagus Komang Edo Setiawan, I Made Anom S. Wijaya*, I Nyoman Sucipta \\ Program Studi Teknik Pertanian, Fakultas Teknologi Pertanian Universitas Udayana, Badung, Bali, Indonesia \\ *email: anomsw@unud.ac.id
}

\begin{abstract}
Abstrak
Lahan pertanian yang berteras dan memiliki luasan per petak kurang dari 0.1 ha, sulit dijangkau oleh mesin-mesin pertanian yang berukuran dan berkapasitas besar. Mesin pemanen padi tipe carry harvester merupakan mesin pertanian yang dapat digunakan pada lahan kecil dan berteras. Tujuan penelitian ini adalahuntuk merancang unit pemotong dan pengarah mesin pemanen padi yang mudah digunakan pada lahan kecil dan berteras. Parameter observasi mesin yang diukur adalah kapasitas lapang efektif (KLE), efektivitas unit pemotong, efektivitas unit pengarah, kosnsumsi bahan bakar dan kehilangan padi pemanenan. Hasil kerja menunjukan efektivitas unit pemotong sebesar $99,56 \%$ dan unit pengarah berjalan dengan baik, yang ditunjukkan oleh presentase efektivitas unit pengarahan sebesar 100\%. Hasil uji kinerja menunjukkan KLE pemanenan mesin ini adalah 0,05 ha/jam, konsumsi bahan bakar sebesar 1,2 1/jam, kehilangan gabah saat pemanenan sebesar $2,1 \%$. Hal tersebut menunjukan bahwa mesin pemanen padi tipe carry harvester pada lahan berteras dan kecil yang tidak bisa dijangkau oleh mesin pemanen besar.
\end{abstract}

Kata kunci:, carry harvester, kapasitas lapang, pemanenan, unit pemotong, unit pengarah

\begin{abstract}
Terraced agricultural field with an area of less than 0.1 ha per plot is difficult to reach by large size and large capacity agricultural machines. A carry type rice harvester is an agricultural machine that can be used on small and terraced field. The aim of this research is to design a cutting and guiding unit of paddy harvesting machine that easy to use on small and terraced paddy field. The parameters observed are effective field capacity (EFC), effectiveness of cutting unit, effectiveness of guiding unit, fuel consumption and harvesting losses. The cutting and guiding unit is running well, which is shown by the percentage effectiveness of cutting unit is $99,56 \%$ and effectiveness of guiding unit is $100 \%$. The performance test results show the EFC harvesting of this machine is 0.05 ha / hour, fuel consumption of $1.21 /$ hour, harvesting is $2.1 \%$. This carry harvester can be used in terraced rice fields that cannot be reached by other big harvesting machines.
\end{abstract}

Keyword:carry harvester, cutting unit, field capacity,guide unit, harvest

\section{PENDAHULUAN}

Tumbuhan padi (Oryza sativa L) termasuk dalam golongan tumbuhan Gramineae, yaitu tumbuhan dengan ciri fisik berupa batang yang tersusun dari beberapa ruas. Tumbuhan padi dalam perkembangbiakannya bersifat merumpun yang artinya tanaman ini akan bertumbuh dari satu tunas menjadi 20-30 atau lebih anakan/tunas baru (Siregar, 1981). Setelah melalui beberapa tahap dalam budidaya tanaman padi, maka tanaman padi akan mencapai pada tahap panen, tahap panen merupakan tahap akhir dari budidaya tanaman padi (L. Musthofa,dkk).

Pada tahap panen diperlukan teknik pemanenan, dalam teknik pemanenan dapat dilakukan dengan cara tradisional maupun modern. Penerapan teknik pemanenan secara tradisional maupun secara modern sejatinya memiliki tujuan yang sama, yaitu untuk memperoleh hasil akhir dari budidaya tanaman padi, yaitu gabah dengan kehilangan hasil panen rendah. Berdasarkan hasil survei Badan Pusat Statistik (BPS, 2007), menunjukkan bahwa susut hasil panen padi di Indonesia masih cukup tinggi, 
yaitu sebesar 11,27 persen yang terjadi pada saat panen (1,57 persen, perontokan (0,98 persen), pengeringan (3,59 persen), penggilingan $(3,07$ persen), penyimpanan (1,68 persen), dan pengangkutan $(0,38$ persen). Perkembangan teknologi dalam teknik pemanenan sejatinya bertujuan untuk meningkatkan kemudahan petani dalam bekerja, yang nantinya dapat meningkatkan kesejahteraan mayoritas petani dan ketahanan pangan nasional maupun lokal, dengan kata lain sistem panen padi tetap sama namun proses didalamnya berubah karena perkembangan teknologi (Sulistiadji ,2007).

Proses pemanenan dapat dilakukan dengan dua macam cara, yaitu cara tradisional dan modern. Pemanenan secara tradisional (manual) menggunakan alat berupa ani-ani dan sabit, sedangkan secara modern (mekanis) menggunakan mesin mower, mesin reaper dan combine harvester (Sulistiadji, 2007). Alat panen ani-ani dan sabit terdiri dari dua bagian utama, yaitu pisau dan kayu nanum memiliki perbedaan bentuk dan pengoprasian (Sulistiadji, 2007). Teknik pemanenan menggunakan ani-ani dan sabit masih banyak diterapkan oleh petani Indonesia, alasannya petani Indonesia masih menggunakan alat tersebut karena belum tersedianya mesin yang sesuai dengan kondisi lahan dan kemampuan ekonomi petani Indonesia.

Lahan yang dimaksud adalah kondisi lahan di Indonesia yang sempit dengan kondisi topografi yang curam dan miring sehingga mesin-mesin terpadu seperti combine harvester belum memungkinkan untuk digunakan dan kemampuan secara ekonomi yang dimaksud adalah petani Indonesia yang banyak belum mampu dalam pengadaan mesin terpadu pada penerapan teknik pemanenan modern (L. Musthofa, dkk).

Teknik pemanenan dengan cara tradisional yang diterapkan oleh petani Indonesia masih memiliki beberapa kelemahan seperti, kebutuhan tenaga orang yang besar dalam pemanenan perhektar, kehilangan gabah pada waktu panen relatif lebih tinggi dibandingkan dengan alat mekanis, kenyamanan bekerja rendah, kapasitas kerja rendah dan biaya panen perhektar relatif lebih tinggi dibandingkan dengan alat mekanis. Kelemahan pada teknik pemanenan tradisional dapat diatasi dengan teknik pemanenan modern, dengan cara penggunaan mesin terpadu berupa combine harvester yang memiliki efisiensi kerja dan waktu yang lebih baik, namun pada teknik pemanenan modern juga memliki beberapa kelemahan seperti, biaya investasi awal yang sangat besar, sumber daya manusia (SDM) untuk pengoprasian yang masih sedikit dan mobilitas mesin yang terbatas (Sulistiadji, 2007).
Kelemahan yang terdapat pada pemanenan tradisional seperti pengoperasian yang membutuhkan tenaga yang lebih banyak, rendahnya kenyamanan kerja dan waktu yang lama dalam proses pemanenan. Selain itu juga melihat dari kelamahan yang ada pada proses pemanenan mekanis atau modern yang membutuhkan biaya yang besar dan tidak mendukungnya lahan di Indonesia terutama lahan terasering, maka muncul ide untuk mengembangkan mesin panen padi yang sederhana dengan dimensi yang lebih kecil, mudah dibawa sehingga memiliki mobilitas tinggi dan sesuai dengan kondisi lahan di Indonesia. Tujuan penelitian adalah mendesain unit pemotong dan unit pengarah pada mesin panen padi yang dapat digunakan pada lahan kecil dan beteras, dan menghitung kinerja mesin rancangan ini.

\section{METODE}

\section{Tempat dan Waktu Penelitian}

Penelitian ini dilakukan dalam dua tahap, yaitu tahap pembuatan alat dan tahap pengujian alat. Pembuatan alat dilaksanakan di Bengkel Las Pak Ion Desa Dauhwaru Kecamatan Jembrana, Kabupaten Jembrana, Bali dimulai dari bulan Pebruari 2015 sampai dengan bulan Juli 2016 dan pengujian alat dilaksanakan di tiga tempat, yaitu dilahan Desa Dauhwaru, Jembrana, Bali, kemudian di lahan sawah Desa Sibang Kaja, Kecamatan Badung Utara, Badung, Bali dan di Desa Kerobokan, Badung, Bali. pada bulan Juli sampai Desember 2016.

\section{Bahan dan Alat}

Bahan - bahan yang digunakan dalam proses perancangan dan pengujian adalah bahan baku yang terdiri dari, mesin pemotong rumput daya $2 \mathrm{HP}$, besi stallbus $600 \times 20 \times 1,4 \mathrm{~mm}$, plat baja $3 \mathrm{~mm}$, plat besi $2 \mathrm{~mm}$, pisau rotari $260 \mathrm{~mm}$, besi silinder $6000 \mathrm{x}$ $8 \mathrm{~mm}$, ass panjang $500 \times 19 \mathrm{~mm}$, ass panjang $500 \mathrm{x}$ $17 \mathrm{~mm}$, baut dan mur $12 \mathrm{~mm}$, baut dan mur $10 \mathrm{~mm}$, baut mur $6 \mathrm{~mm}$, roda sepeda 20 inchi, shock beker $200 \mathrm{~mm}$, bearing $20 \mathrm{~mm}$, bearing $17 \mathrm{~mm}$, bos 17 $\mathrm{mm}$, besi silinder 50 inchi dan tanaman padi yang siap panen. Alat yang digunakan dalam perancangandan pengujian adalah bahan baku yang terdiri dari mesin las Rhino 120 Ampere, gerinda tangan Bosch dan gerinda duduk, bor listrik, kunci pass $12,14,17$, tang, palu, obeng, meja kerja, mata bor, electrode, stopwhact, mistar, timbangan.

\section{Tahap Penelitian}


Diagram alir dalam tahap penelitian rancangan ini adalah sebagai berikut:

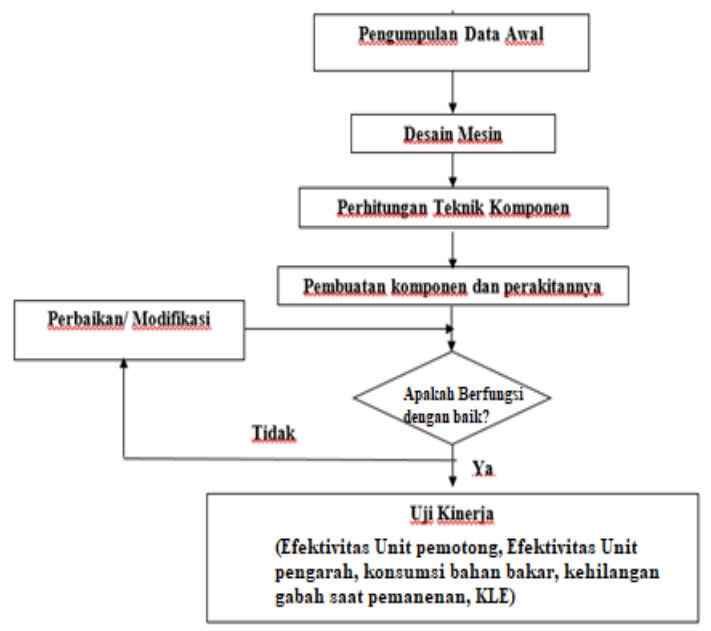

Gambar 1. Diagram alir tahap penelitian

\section{Parameter Uji Kinerja}

Uji kinerja dilakukan untuk mengetahui dan mendapat hasil potongan padi yang sesuai dengan harapan. Dalam hal ini diharapkan kinerja mesin dapat menghasilkan potongan padi yang merata dan perebahan hasil potongan padi yang rapi kesatu arah tanpa ada potongan padi yang terlempar pada saat terpotong. Uji kinerja yang dilakukakn meliputi: Kapasitas lapang efektif, kecepatan jalan pemanenan, persentase susut pemanenan, persentase batang padi terpotong, presentase batang padi tidak terpotong, efektivitas kinerja pengarah dan konsumsi bahan bakar mesin.

\section{Kapasitas Lapang Efektif}

Menghitung Kapasitas Lapang Efektif sebagai berikut:

Keterangan:

$$
\mathrm{KLE}=\frac{A}{t}
$$

KLE : Kapasitas lapang efektif (Ha/jam)

A : Luas areal pemanenan padi (Ha)

$\mathrm{t} \quad$ : Waktu total pemanenan (jam)

\section{Persentase Kehilangan Pemanenan}

Menghitung persentase kehilangan gabah saat pemanenan sebagai berikut:

$\mathrm{WL}=\frac{W 1+W 2}{Y} \times 100 \%$

Keterangan :

WL: presentase susut pemanenan (\%)

W1: bobot padi yang tidak terpanen $\left(\mathrm{g} / \mathrm{m}^{2}\right)$

W2:bobot padi yang rontok karenapemanenan $\left(\mathrm{g} / \mathrm{m}^{2}\right)$

Y: bobot padi hasil padi dari ubinan $\left(\mathrm{g} / \mathrm{m}^{2}\right)$

\section{Efektivitas Kinerja Pemotong}

Presentase batang terpotong :

$\mathrm{BT}=\frac{\text { jumlah batang terpotong per rumpun }}{\text { jumlah batang awal per rumpun }} \times 100 \%$

Keterangan:

BT: Batang terpotong $(\%)$

\section{Efektivitas Kinerja Pengarah}

$\mathrm{HPT}=\frac{\text { jumlah batang padi yang terarahkan }}{\text { jumlah batang padi yag terpotong }} \times 100 \%$

Keterangan :

HPT : Hasil potongan padi terarahkan (\%)

\section{Konsumsi Bahan Bakar}

Untuk menghitung konsumsi bahan bakar sebagai berikut:

$$
\mathrm{FC}=\frac{F V}{t 2}
$$

Keterangan:

FC : Pemakaian bahan bakar (liter/jam)

FV : Volume bahan bakar (liter)

$\mathrm{t}_{2} \quad$ : Waktu kerja motor penggerak (jam)

\section{HASIL DAN PEMBAHASAN}

\section{Unit Motor Penggerak}

Sumber tenaga penggerak pisau menggunakan motor bensin berkapasitas 2 PK dengan kecepatan putar poros mesin adalah maksimum $1100 \mathrm{rpm}$. Transmisi daya dari sumber penggerak ke pisau berupa dengan system kabel baja dan baja silinder, kabel baja dengan panjang $60 \mathrm{~cm}$ dan baja silinder berupa as diameter $2 \mathrm{~cm} \mathrm{~mm}$. Pada system ini ada reduksi putaran (rpm motor $1110 \mathrm{rpm}$, rpm unit pemotong $600 \mathrm{rpm}$ ).

\section{Unit Pemotong}

Unit pemotong berbentuk pisau bulat dengan diameter lingkaran sebesar $26 \mathrm{~cm}$ dengan sisi bagian luar berupa gerigi pemotong dengan panjang gigi 2 $\mathrm{cm}$. Pisau memiliki ketebalan $5 \mathrm{~mm}$ dan terbuat dari besi baja. Ukuran panjang pisau dan kerapatan pada unit pemotong secara teknis mampu memotong setiap satu rumpun padi dalam sekali putaran, selain itu bahan pisau berupa baja dapat diasah sesuai kebutuhan sehingga menjamin efektifitas proses pemotongan rumpun padi. Unit pemotong terpasang pada bagian depan mesin carry harvester ini, dengan jarak $2 \mathrm{~mm}$ dari unit pengarah. Jarak antara pisau pemotong dan unit pengarah tersebut adalah jarak 
ideal agar hasil potongan batang padi tidak terselip diatas pisau, dan agar tidak ada gesekan antara pisau pemotong dengan unit pengarah.. Fungsi mesin panen yang pertama adalah memotong batang tanaman padi. Fungsi pemotongan ini dilakukan oleh pisau rotari piringan yang mendapatkan tenaga dari mesin motor bakar dengan perantaraan transmisi (Simon Ka'ka dkk. 2017)

Mekanisme kerja unit pemotong untuk menjamin efisiense dan kualitas hasil kerja unit ini adalah :

a. Motor bensin yang merupakan sumber tenaga penggerak dihidupkan menyebabkan poros mesin berputar, putaran poros ditransmisikan ke putaran pisau. Putaran pisau sebesar $600 \mathrm{rpm}$ sudah mampu memotong batang padi secara keseluruhan

b. Putaran pisau pemotong berlawan arah jarum jam, dengan teknik pemotong secara mengiris sedikit demi sedikit batang padi. Proses pisau memotong batang padi akibat perputaran pisau dan gerak maju mesin secara keseluruhan. Pemotongan dengan teknik tersebut bertujuan agar hasil potongan padi tidak berhamburan.

c. Putaran pisau pemotong juga membantu untuk menggiring hasil potongan kesisi luar mesin

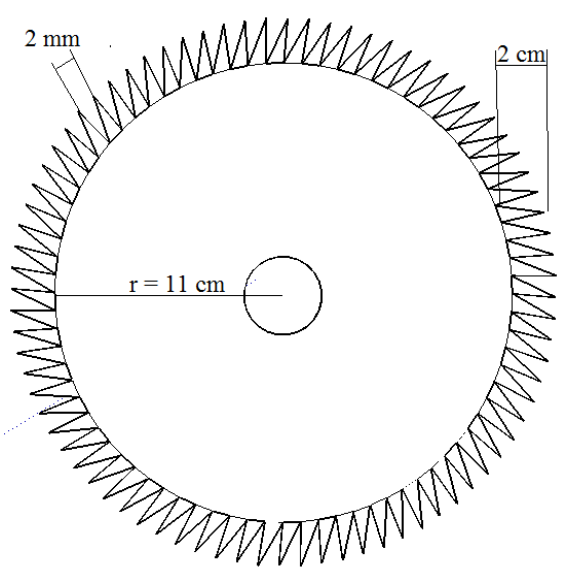

Gambar 2. Pisau Pemotong

\section{Unit Pengarah}

Unit pengarah terdiri dari 2 bentuk, yaitu bentuk segitiga prisma di bagian depan sampai dititik tengah unit pemotong, kemudian berbentuk leter $\mathrm{S}$ pada bagian tengah pisau pemotong sampai kebelakang sepanjang $35 \mathrm{~cm}$. Kemiringan pisau pemotong ideal adalah $30^{\circ}$, kemiringan unit pengarah dapat diatur sesuai kebutuhan pada saat proses pemotongan batang padi.

Pengarah yang bentuk segitiga prisma bekerja mengarahkan, mengumpan dan merebahkan batang padi ke sisi kiri. Hal ini berakibat dapat memudahkan unit pemotong menjangkau batang padi pada proses awal pemotongan, sehingga efektifitas proses menjadi maksimal. Proses bekerjanya unit pengarah sebagai akibat gerak maju mesin secara keseluruhan saat beroperasi memotong batang padi.

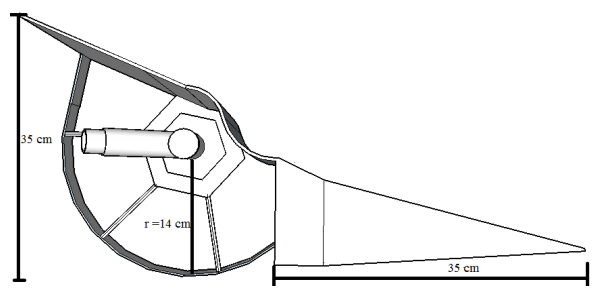

Gambar 3. Unit Pengarah

\section{Unit Rangka Utama}

Rangka Utama terbuat dari besi galpanis $4 \times 2 \times 0.2$ $\mathrm{cm}$, dimensi rangka utama $\mathrm{p} \times 1$ aladalah $80 \times 10$ $\mathrm{cm}$. rangka utama terdiri dari poros tengah penyanggaa unit pengarah dan rangka letak sasis roda. Struktur poros tengah rangka didesain agar dapat mengatur kemiringan unit pengarah dan struktur lebar rangka sasis roda didesain agar tidak lebih dari rata-rata jarak antar rumpun padi.

Titik berat mesin ini ada pada bagian sasis roda, semua beban bertumpu pada titik tersebut. Untuk mengurangi beban pada titik tersebut maka ditambahkan suspense berupa shockbeaker. Konstruksi rangka yang demikian mampu menyangga keseluruhan bagian mesin dan menjaga kesetimbangan mesin, sehingga pada saat mesin dioperasikan tidak terjadi mjomen gaya yang mengakibatkan mmesin tidak seimbang dan menjaga keselamatan kerja operator.

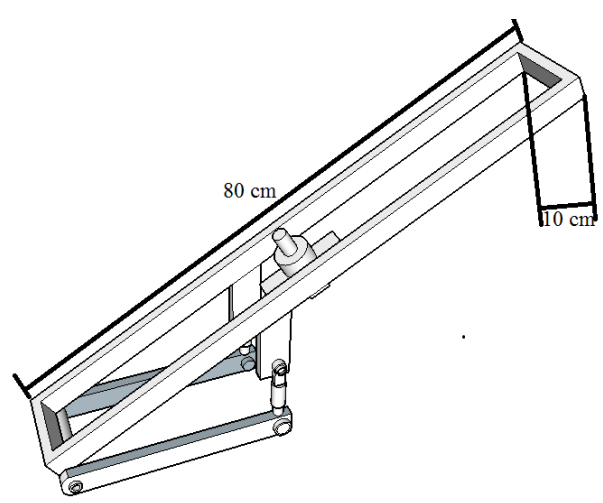

Gambar 4. Unit Rangka Utama

\section{Kapasitas Lapang Efektif}

Kapasitas lapang efektif alat diperoleh dengan membagi luas areal pemanenan yang terpotong dengan waktu pemotongan. Hasil penelitian yang telah dilakukan diperoleh kapasitas lapang efektif 
mesin panen padi adalah $0,05 \mathrm{Ha} / \mathrm{jam}$ sedangkan dengan cara manual diperoleh kapasitas efektif yaitu $0,025 \mathrm{Ha} / \mathrm{jam}$. Hal ini menunjukkan bahwa alat ini bisa meningkatkan kerja 2 kali lipat dari pada memotong padi secara manual. Kinerja mesin ini lebih rendah dari kinerja mesin panen hasil perancangan Simon Ka'ka (2017), kapasitas kerja mesin rancangan Simon Ka'ka adalah 0,041 Ha/jam. Selain itu, kapasitas itu kapasitas ini juga lebih rendah dari mesin tipe combine harvester (Iqbal Maksudi et al. 2018).

Sistim pemotongan batang padi oleh mesin hasil perancangan adalah satu alur dalam setiasp lintasan dengan kecepatan mesin sesuai dengan kecepatan orang berjalan $(3,6 \mathrm{~km} / \mathrm{jam})$. Kinerja bagian-bagian dari mesin yang berupa sumber tenaga penggerak, unit pengarah, pisau pemotong yang dirangkai pada kerangka mampu bersinergi secara baik dalam melakukan proses pemanenan padi dengan memotong batang padi perrumpun dalam sekali proses. Secara keseluruhan mesin hasil perancangan tetap seimbang selama mesin dioperasikan untuk memotong satu rumpun batang padi, sehingga waktu panen mempergunakan mesin ini. (Tabel 1) menjadi lebih pendek dari pada pemanenan secara manual mempergunakan sabit (Tabel 2). Hal ini nampak dari jumlah batang padi yang tidak terpotong dalam satu rumpun yang berjumlah $0-$ 2,6\% (Tabel 3).

Tabel 1. Kapasitas Lapang Efektif Pemanenan Secara Mekanis

\begin{tabular}{c|cccc|c}
\hline Ulangan & $\begin{array}{c}\text { Luas lahan } \\
\text { pemanenan (Ha) }\end{array}$ & Detik & $\begin{array}{c}\text { Waktu pemanenan } \\
\text { Menit }\end{array}$ & Jam & $\begin{array}{c}\text { Kapasitas lapang } \\
\text { efektif (Ha/Jam) }\end{array}$ \\
\hline 1 & 0,01 & 792 & 13,43 & 0,22 & 0,045 \\
2 & 0,01 & 725 & 12,08 & 0,20 & 0,050 \\
3 & 0,01 & 667 & 11,12 & 0,19 & 0,053 \\
& & Rata-rata & & & 0,05 \\
& & SD & & & 0,004 \\
& & CV (\%) & & & 8.19 \\
\hline
\end{tabular}

Dari Tabel diatas menujukan bahwa ada peningkatan nilai kapasitas lapang efektif selama 3 kali ulangan. Rata-rata nilai Kapasitas Lapang Efektif 0,05 ha/jam

Tabel 2. Kapasitas Lapang Efektif Pemanenan Mecara Manual.

\begin{tabular}{cccccc} 
Ulangan & $\begin{array}{c}\text { Luas lahan } \\
\text { pemanenan (Ha) }\end{array}$ & Detik & $\begin{array}{c}\text { Waktu pemanenan } \\
\text { Menit }\end{array}$ & Jam & $\begin{array}{c}\text { Kapasitas lapang efektif } \\
\text { (Ha/Jam) }\end{array}$ \\
\hline 1 & 0,01 & 1404 & 23,4 & 0,39 & 0,026 \\
2 & 0,01 & 1548 & 25,8 & 0,43 & 0,023 \\
3 & 0,01 & 1440 & 24 & 0,40 & 0,025 \\
& & & & 0,025 \\
& & & & 0,002 \\
& & & & 6.19 \\
\hline
\end{tabular}

\section{Efektivitas Kinerja Unit Pemotong}

Pada Tabel 3 menunjukan bahwa efektivitas kinerja unit pemotong sudah sangat baik dengan nilai ratarata $99,56 \pm 1,01 \%$. Persentase tersebut menunjukan semua rumpun yang ada dilahan sudah terpotong dan meninggalkan sedikit sisa pada yang tidak terpotong pada satu rumpun sebanyak $0-2,6$ $\%$, seperti sudah diungkap di depan. Kehilangan tertinggal pada mesin Mini Combine harvester yaitu $1,44 \% \pm 0.40 \%$ (Valentines et al. 2016). Pisau pemotong berbentuk gerigi yang berputar pada kecepatan sekitar $600 \mathrm{rpm}$ sangat efektif melakukan pemotongan rumpun batang padi, karena gaya sentrifugal yang dihasilkan dari putaran pisau yang dikombinasikan dengan gerak maju mesin mampu melakukan pekerjaan pemotongan rumpun batang padi. Selain itu, bahan pisau dengan ketajaman gerigi sangat mendukung kinerja pemotongan batang padi.

\section{Efektivitas Kinerja Unit Pengarah}

Pada Tabel 4 menunjukan bahwa nilai rata-rata yang batang padi yang terarahkan sudah semuanya tearahkan sesuai perancangan, jumlah batang padi terarahkan secara sempurna atau $100 \%$, dengan nilai variansi 0 yang menunjukan bahwa kinerja pengarah 
konstan dan baik pada saat dioprasikan. Unit pengarah mampu bekerja sangat optimal bersama gerakan maju mesin secara keseluruhan dengan kecepatan maju sesui dengan kecepatan oprator mesin berjalan.

Tabel 3. Presentase Efektivitas Kinerja Pemotong

\begin{tabular}{ccccc|c} 
Ulangan & $\begin{array}{l}\text { Panjang } \\
\text { lintasan } \\
(\mathbf{m})\end{array}$ & $\begin{array}{l}\text { Jumlah } \\
\text { rumpun }\end{array}$ & $\begin{array}{l}\text { Rumpun } \\
\text { terpotong }\end{array}$ & Persentase (\%) \\
\hline 1 & 10 & 45 & 45 & 100 \\
2 & 10 & 40 & 40 & 100 \\
3 & 10 & 38 & 37 & 97.4 \\
4 & 10 & 44 & 44 & 100 \\
5 & 10 & 45 & 45 & 100 \\
6 & 10 & 40 & 40 & 100 \\
7 & 10 & 45 & 44 & 100 \\
8 & 10 & 40 & 40 & 100 \\
9 & 10 & 39 & 39 & 100 \\
10 & 10 & 42 & 41 & 97.4 \\
11 & 10 & 37 & 37 & 100 \\
12 & 10 & 40 & 40 & 100 \\
\multicolumn{5}{c}{ Rata-rata presentase (\%) } \\
CD & 99,56 \\
\hline
\end{tabular}

Tabel 4. Presentase Efektivitas Kinerja Pengarah

\begin{tabular}{|c|cccc|}
\hline Ulangan & $\begin{array}{c}\text { Panjang } \\
\text { lintasan } \\
(\mathbf{m})\end{array}$ & $\begin{array}{c}\text { Jumlah } \\
\text { rumpun } \\
\text { Terpotong }\end{array}$ & $\begin{array}{c}\text { Rumpun } \\
\text { Terarahkan }\end{array}$ & $\begin{array}{c}\text { Persentase } \\
(\%)\end{array}$ \\
1 & 10 & 45 & 45 & 100 \\
2 & 10 & 40 & 40 & 100 \\
3 & 10 & 37 & 37 & 100 \\
4 & 10 & 44 & 44 & 100 \\
5 & 10 & 45 & 45 & 100 \\
6 & 10 & 40 & 40 & 100 \\
7 & 10 & 45 & 44 & 100 \\
8 & 10 & 40 & 40 & 100 \\
9 & 10 & 39 & 39 & 100 \\
10 & 10 & 41 & 41 & 100 \\
11 & 10 & 37 & 37 & 100 \\
12 & 10 & 40 & 40 & 100 \\
& Rata-rata presentase (\%) & & 100 \\
& \multicolumn{5}{c}{ SD } \\
\multicolumn{5}{c}{ CV (\%) } \\
\hline
\end{tabular}

\section{Konsumsi Bahan Bakar}

Konsumsi bahan bakar perjam adalah 1,2 liter, konsumsi bahan bakar dipengaruhi oleh besarnya daya mesin yang dikeluarkan. Semakin besar daya mesin dan semakin kecil kapasitas lapang maka semakin kecil efektifitas penggunaan bahan bakar. Alternatif memperbesar efesiensi penggunaan bahan bakar dilakukan dengan cara menetapkan daya mesin yang digunakan sebesar 2 PK.

\section{Spesifikasi Carry Havester}

Penelitian perancangan mesin panen padi tipe Carry Harvester mengalami beberapa proses perancangan untuk mendapatkan spesifikasi akhir yang sesuai dengan tujuan penelitian.Tahap akhir perancangan mesin carry harvester mengunakan sitem pengarahan kontruksi alur, yang dimana kontruksi ini dibuat mengikuti alur jatuhnya hasil potongan padi, kontruksi tahap akhir ini lebih baik daripada kontruksi sebelumnya, sehingga hasil rancangan tahap akhir ini dapat melebihi kapasitas lapang efektif pemanenan secaraa konvensional rancangan tahap akhir ini memiliki spesifikasi sebagai berikut:

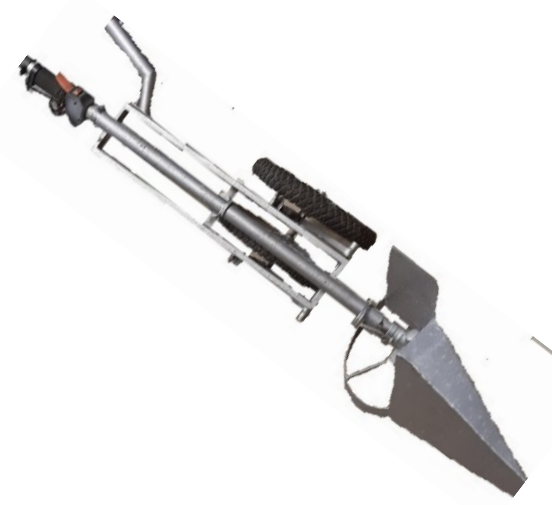

Gambar 5. Hasil Rancangan Mesin Pemanen Padi

Tabel 5. Spesifikasi Carry Harvester

\begin{tabular}{rlc} 
No & Spesifikasi & 1 baris \\
1 & Tenaga penggerak (Hp) & 2 \\
2 & Panjang (mm) & 2100 \\
3 & Lebar (mm) & 350 \\
4 & Tinggi (mm) & 800 \\
5 & Lebar kerja (m) & 40 \\
6 & Bobot keseluruhan(kg) & 25 \\
7 & Kecepatan maju(km/jam) & $1,3-1,5$ \\
8 & Kapasitas kerja (Ha/jam) & $0,045-0,055$ \\
9 & Susut tercecer (\%) & Kurang $2,5 \%$ \\
10 & Kecepatan pisau x kecepatan maju & 2 kali \\
11 & Pemakaian bahan bakar (liter/jam) & 1,2 \\
12 & Efektifitas pemotong (\%) & 99,56 \\
13 & Efektivitas Pengarah (\%) & 100 \\
\hline
\end{tabular}

Spesifikasi mesin diatas menunjukan bahwa kapasitas kinerkja pemanenan sudah mencapai SNI Carry Harvester, yaitu sudah melebihi $0,05 \mathrm{Ha} / \mathrm{jam}$, dengan susut pemanenan kurang dari 2,5\%.

\section{KESIMPULAN DAN SARAN}

\section{Kesimpulan}

Efektivitas kinerja unit pemotong dan pengarah bekerja dengan baik, dengan presentase efektivitas unit pemotong $99.56 \%$ dan unit pengarah sebesar $100 \%$. Efektivitas kinerja pemanenan mekanis menggunakan carry harvester lebih baik besar dibandingkan pemanenan manual. Kapasitas lapang efektif pemanenan mekanis mencapai 0.05 ha/jam, dibandingkan pemanenan manual yang hanya mencapai $0.025 \mathrm{ha} / \mathrm{jam}$. 


\section{Saran}

Perlu adanya pengembangan desain pada bagian unit pengarah, agar padi yang diarahkan dapat terkumpul dengan baik pada suatu wadah, agar tidak lagi memungut pada saat setelah pemotongan. Penggunaan roda perlu dikembangkan agar mudah digunakan pada lahan sawah padi pada saat siap dipanen.

\section{Daftar Pustaka}

Alizadeh MR dan Allameh A. 2013. Evaluating rice losses in various harvesting practices. International Research Journal of Applied and Basic Sciences [Internet]. [diunduh 2014 Jan 20]; 4 (4): 894-901. Tersedia pada: http://www.irajabs.com.

[BPS] Badan Pusat Statistik. 2012. Tanaman Pangan [Internet]; [diunduh 2014 Des 8]. Tersedia pada : www.bps.go.id.

Daywin JF, Sitompul G, Hidayat I. 1992. Mesinmesin Budidaya Pertanian. Bogor (ID): IPB Press.

Hasbi. 2012. Perbaikan teknologi pascapanen padi di lahan suboptimal. Jurnal Lahan Suboptimal [Internet]. [diunduh 2014 Agu 13]. ISSN: 2302-3015. Vol. 1, No.2: 186196, Oktober 2012. Tersedia pada: www.pur-plso-unsri.org/upload_file/25-801-PB.pdf.

Iqbal Maksudi, Indra, T. Fauzi. 2018. Efektivtas Penggunaan Mesin Panen (Combine Harvester) Pada Pemanenan Padi Di Kaupaten Pidie Jaya. Jurnal Ilmiah
Mahasiswa Pertanian, Vol. 3, No. 1, Februari 2018: $140-146$

Kementrian Pertanian. 2012. Perencanaan Tenaga

Kerja Sektor Pertanian 2012-

Lahan Suboptimal [Internet]. [diunduh 2014 Agu 13]. ISSN: 2302-

Lutfhi, Musthofa. E-jurnal Rancang Bangun Mesin Pemanen Padi. FTP-Universitas Brawijaya. Jawa Timur.

[SNI] Standar Nasional Indonesia. 2010. Mesin Pemanen Padi Tipe Sandang, Syarat Mutu dan Cara Uji (SNI 7600:2010). Jakarta (ID): Badan Standarisasi Nasional.

Simon Ka'ka, Luther Sonda, Donatus Langga Pase, M. Aryasangga, Analisis Desain dan Biaya Mesin Pemotong Padi. SINERGI NO. 1, TAHUN 15, APRIL 2017

Srivastava AK, Goering CE, Rohrbach RP. 1996. Engineering Principles of Standarisasi Nasional.

Sulistiadji K. 2007. Alat dan Mesin Panen dan Perontokan Padi di Indonesia. Syarat Mutu dan Cara Uji (SNI 7600:2010). Jakarta (ID): Badan

Valentinus I.W Tandi Pondan, Lady C.Ch.E Lengkey, Daniel P.M. 2016. Kajian Kehilangan Hasil Pada Pemanenan Padi Sawah Menggunakan Mesin Mini Combine Harvester MAXXI-M (Studi Kasus di DesaTorout Kecamatan Tompaso Baru Kabupaten Minahasa Selatan). Warta Penelitian Vol.37 No.1 